\title{
Using forum theatre to teach communication skills within an undergraduate pharmacy curriculum : a qualitative evaluation of students' feedback
}

\author{
Sabrina Anne Jacob, University of Strathclyde \\ James Larter, RolePlay UK \\ Andrew Blair, RolePlay UK \\ Anne Boyter, University of Strathclyde
}


Pharmacist-patient communication has traditionally been unidirectional, ${ }^{1-3}$ with numerous studies illustrating that pharmacists use technical jargon, ${ }^{4}$ display feeble responses to emotional prompts, ${ }^{5}$ and control the interaction and content by using close-ended questions. ${ }^{6-8}$ There is also minimal effort to engage with or elicit feedback from patients about their preference or concerns with regard to their medication..$^{5,6,9,10}$ Indeed, pharmacists tend to focus on transferring information to patients based on what they perceive to be important. ${ }^{11,12}$ This approach to communication has thus impeded effective engagement with patients, and could affect adherence. ${ }^{6,10}$ With the shift from the traditional biomedical model of care long adopted by pharmacists, to a patient-centered model which facilitates the provision of pharmaceutical care, ${ }^{13-17}$ there is a need for pharmacists to similarly move away from communication styles which focus on the transmission of information, to one that adopts a transactional model. ${ }^{1,12,17}$

The importance of pharmacists as communicators is underlined in the World Health Organization's seven-star concept, which states that pharmacists should be active communicators who employ verbal, non-verbal, and listening skills. ${ }^{18}$ This has been echoed by the International Pharmaceutical Federation, who stipulate that educational programs should prepare future pharmacists to have adequate social and communication skills. ${ }^{19}$ Indeed, research has shown that effective communication can lead to increased adherence, better health outcomes, increased patient satisfaction, a better understanding of treatment, and increased patient engagement in therapeutic decisions..$^{2,6,9,17,20-}$ 24 A number of pharmacy curricula, however, focus on developing students' medication-related competencies, as opposed to their relational or social skills - skills which would have a greater bearing on patient engagement. ${ }^{1,8,9}$ There has also been a reliance on didactic teaching methods to teach communication skills, ${ }^{8,16}$ which may not be as effective as active-learning approaches. ${ }^{24}$

Patient-pharmacist interactions are not scripted communications, and are instead a dynamic exchange occurring in an equally dynamic environment. ${ }^{12}$ While not discounting the effectiveness of using simulated or standardized patients (SPs) to teach communication skills, ${ }^{22,25-27}$ SPs nonetheless give scripted responses to students, which belie the true nature of the interactions which take place in a pharmacy or at the bedside. ${ }^{12,28}$ It has also been noted that for deep-learning to occur, there should be 
1 active participation and application of knowledge by the learner. ${ }^{24}\{$ Reece, $2007 \# 83145\}\{$ Biggs, 2011

$2 \# 83146$ \} This underlines the value of employing forum theatre to teach communication skills, as the

3 very nature of educational drama 'demand involvement in action and reflection on this action. ${ }^{29}$ Forum

4 theatre, which has been used successfully in healthcare education, employs the dramatization of

5 scenarios to highlight the gaps in communication in real-world practice, and stimulates debate on ways

6 to overcome these deficiencies. ${ }^{24}$ Here, actors use improvisational techniques and role-playing, which

7 has been found to be effective at increasing students' competence and confidence in their patient-care

8 skills; ${ }^{30-35}$ whereby students are taught how to think on their feet and adapt the exchange accordingly..$^{28}$

9 As noted by Middlewick et al, It is the ability for drama to link with the emotions and the universal appeal of theatre that makes forum theatre such a potentially powerful educational tool. ${ }^{24}$ The primary purpose of this article is to describe the use of forum theatre to teach communication skills to future pharmacists, and to highlight the findings of students' perceptions of the communications workshops.

\section{Educational activity and setting}

Setting

The School of Pharmacy (SoP) collaborated with RolePlay UK, a commercial organization which specializes in live learning techniques facilitated by actors to run workshops for students in the first three years of study in the pharmacy degree. In this School, students start the first year of the programme in Year 2. The workshops were introduced sequentially from 2014, with all three years implemented by 2016 and one workshop conducted per year. The workshops utilize a combination of formats/methods for delivery such as introductory plenary, group discussion, forum theatre, drama, and immediate feedback. The forum theatre method involves students watching a brief simulated pharmacist-patient interaction, followed by multiple redirections of the scenario to change and improve the interaction. Actors facilitate each session. Staff from the SoP were not present during the sessions as the actors were the experts in the delivery of forum theatre. The SoP made the decision that these workshops should concentrate on communication skills which the students could then put into the 


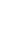

pharmacy context in subsequent workshops. Staff from the SoP were involved in the design of the scenarios.

Initially students learned about their own communication style before demonstrating how to flex this to communicate with others. 'Flexing' is a communication style whereby the communicator adjusts his/her own dominant style according to the style of the person he/she is communicating with. ${ }^{36}$ This is coupled with learning about how to respond to symptoms of minor ailments in a structured manner using forum theatre. In Year 3, students redirect forum theatre scenarios which depict issues related to dealing with difficult situations, issues of confidentiality, and communicating with patients; and are given an introduction to leadership. In Year 4, students role-play consultations and interview situations with the actors (Table 1). Second and subsequent workshops start with a reflection on what was learned in the previous year and what students hope to see in the current year. These skills are then consolidated in sessions with pharmacy practitioners and during experiential learning. No assessment is undertaken after the workshops to determine the skills gained by students, however this may be captured during tests, final examinations, and Objective Structured Clinical Examinations (OSCEs) using case examples, communication skill stations and descriptions of problem-solving.

\section{Data and participants}

At the end of the workshops, students gave their feedback via an anonymous online (Qualtrics, Provo, UT) ${ }^{37}$ quantitative survey. As part of the survey, students were asked to give responses to two open-ended questions: 1) What part of the workshops was most useful for you?, and 2) What could improve the content and/or delivery of the communication workshops? Students were also asked if they had any additional feedback to give. A link to the survey was emailed to students the day after each workshop, and a general reminder was sent after one week. Students were invited to fill in the survey form, voluntarily, in an email from the Director of Teaching. The survey was closed after two weeks.

\section{Data transcription and analysis}


3 is debate as to the use of quantitative or qualitative methods to analyze open-ended questions, we believe

4 a qualitative approach is more suitable as it allows a more comprehensive and user-oriented method of 5 assessing students' satisfaction with the workshops. ${ }^{38}$ Qualitative methods will also provide contextual 6 understanding of students' responses, provide a richer description of students' perceptions, and leave the perspectives of students intact. ${ }^{39-41}$ All responses were imported verbatim into NVivo 11 Software (QSR International Pty Ltd., Version 10, 2012) ${ }^{42}$ where three stages of coding - open, axial, and selective, were performed by author SAJ using inductive reasoning, to identify themes. ${ }^{43}$ This was then verified by author ACB to ensure relevance with identified themes. Quotations by students were edited on a limited basis to remove content that did not convey meaning (repeated words, editing errors etc.) and to correct for grammar. An ellipsis mark was used to note removal of such extraneous content. Square brackets were used in quotations to supply words omitted by the respondent or to replace sensitive information where names were mentioned. Students are identified using their year of study (e.g. Y4), year of attending the workshop (e.g. 18), and survey response number as captured by Qualtrics. The Departmental Ethics committee stated that full ethical approval was not required as this was an evaluation of a learning and teaching innovation.

\section{Findings}

A total of 468 students responded to the quantitative survey (response rate $42.4 \%$ ), and of these, 91.2\% left written comments (427/468), resulting in a total of 752 comments. Table 2 illustrates the number of comments received. As students progressed through the curriculum, individual students may have responded to more than one questionnaire. Responses ranged from a single remark, to six lines of description (Times New Roman 12-point type, 20cm column). Thematic analysis revealed five key themes, which are described below. 
Theme 1: Students thought the workshops were useful in facilitating the development of communication skills

Learning about people's 'currencies', the four different personalities, and how to flex their communication styles according to the corresponding personalities, were elements of the workshop students found most beneficial. It made them cognizant of the fact that different people's behaviors were motivated by various underlying factors. This then evoked in students a consciousness that they had to tailor or mirror their behavior and communication styles according to different scenarios, as well as patients' own attitudes, moods, and communication styles. There was an acknowledgement that this was to ensure effective communication, and that the patients receive the best service and return to the pharmacy for their future healthcare needs. As one student wrote,

"Elearning about identifying different people and learning the general concept of adjusting to others' style. I hope this will make me a better communicator in not just my job but in [my] daily life. " (Y2-1424)

The session where they discovered their own communication styles and what drives it, was also found to be helpful to be able to adapt according to different patient behaviors. In learning their own styles, it helped students discover their strengths and prompted them to work on their weaknesses, including those they were previously unaware of. A few students also found learning how to direct conversations, the difference between close and open-ended questions, and how to use the latter to elicit information from patients, as useful tools to assist them in ensuring the correct medication was given to patients. Similarly, the topic on non-verbal communication skills such as body language, how it may be perceived by others, and how to alter it to bring about effective communication, was also thought to be valuable.

Year 3 students found the topic on leadership useful as it not only made them understand the different methods of being an effective leader in the work environment, but also how to influence other people when not in the position of power or authority. The majority of Year 4 students found the mock interview sessions very helpful as they previously lacked the skills on how to engage with, and build rapport with the interviewers. The session made them more comfortable with the skills they currently
Formatted: Justified, Widow/Orphan control, Adjust space between Latin and Asian text, Adjust space between Asian text and numbers, Tab stops: Not at $1.27 \mathrm{~cm}+2.54 \mathrm{~cm}+3.81 \mathrm{~cm}+5.08 \mathrm{~cm}+6.35 \mathrm{~cm}+$ $7.62 \mathrm{~cm}+8.89 \mathrm{~cm}+10.16 \mathrm{~cm}+11.43 \mathrm{~cm}+12.7 \mathrm{~cm}$ $+13.97 \mathrm{~cm}+15.24 \mathrm{~cm}+16.51 \mathrm{~cm}+17.78 \mathrm{~cm}$ 
1 possessed, and taught them how to express them. It was also something that students thoughtfelt they

2 previously never had the opportunity to practice as they mostly practiced their clinical consultation

3 skills. After the sessions, some students proclaimed they felt more confident as it helped them see how

4 others viewed themselves, identified their shortcomings, provided tips on what information to provide

5 and how to approach the interview, as well as allowed them to practice in a non-intimidating

6 environment. This is illustrated in the following sentence:

"As I was nervous about the upcoming hospital interview, I found that the mock interview was

8 fantastic for preparation. It gave me inspiration for what to mention to help make me stand out. I have

realised my strengths and weaknesses which I can utilise to improve my persona and hopefully impress the interviewer. Overall, my confidence has been boosted, I have some preparation tips and the ideas I require to hopefully ace the interview and gain a placement." (Y4-18-29)

\section{Theme 2: Workshops encouraged student reflection}

Analysis of the open-ended responses revealed that the sessions encouraged reflection as they indirectly prompted students to reflect on their own communication style, and approach to dealing with people. It provoked an internal discussion on how a pharmacist should and should not behave (for instance not rushing into a conversation), and instilled an awareness on how making small changes to their communication style could affect the way patients respond. Students thoughtfelt this spurred them to strive to be better communicators and pharmacists. One student explained, "the most useful parts of the workshops, for me, were the sections whereby the actors from RolePlay UK would act out a scene and we had to stop them and suggest where things can be improved. This made it very easy to identify myself with the situations and it was very effective for self-reflection as the situations were such accurate depictions of complex, yet common situations which occur in practice often. This visual aided a clearer understanding of self and most importantly, self-improvement." (Y3-17-29) This reflection carried on beyond the workshop, with a few reporting that they became more mindful while at their part-time jobs in the pharmacy, and were more aware of the different personalities they encountered which then prompted them to alter their behavior and communication styles accordingly.
Formatted: Justified

Formatted: Indent: First line: $0 \mathrm{~cm}$, Don't adjust space between Latin and Asian text, Don't adjust space between Asian text and numbers, Tab stops: $1.27 \mathrm{~cm}$ Left $+2.54 \mathrm{~cm}$, Left $+3.81 \mathrm{~cm}$, Left $+5.08 \mathrm{~cm}$, Left + $6.35 \mathrm{~cm}$, Left $+7.62 \mathrm{~cm}$, Left $+8.89 \mathrm{~cm}$, Left +10.16 $\mathrm{cm}$, Left $+11.43 \mathrm{~cm}$, Left $+12.7 \mathrm{~cm}$, Left $+13.97 \mathrm{~cm}$, Left $+15.24 \mathrm{~cm}$, Left $+16.51 \mathrm{~cm}$, Left $+17.78 \mathrm{~cm}$, Left

Formatted: Font: (Default) Times New Roman, 11 pt Italic 
2 would act out a scene and we had to stop them and suggest where things can be improved. This made

Theme 3: Students appreciated the feedback provided

Many students commented that they appreciated the feedback and advice received from the actors as well as their peers on their techniques and communication styles, stating that the feedback was very constructive, relevant, and useful. Students appreciated the fact that the feedback was instant and personal, but noted that they not only appreciated feedback on their shortcomings but also on their strengths, as it reassured them that they were on the right track. While students acknowledged the usefulness in receiving feedback from and interacting with their peers, a few appreciated working with non-peers as they felt that they usually did not take things seriously when interacting with their friends. Feedback received from the actors were also perceived to be more advanced compared to that of their peers.

\section{Theme 4: Students thoughtfelt the live, interactive nature of the workshops enhanced their learning}

The live, interactive nature of the workshops received praise from most students, who remarked that it provided a fun and interesting method to learn communication skills, and enabled them to see first-hand the skills being taught put into action, with one writing, :

"I found being able to review the scenarios acted out and change the behaviours of the characters particularly useful. It let me see how attitudes and phrasing of information could impact how a patient/customer would react to a situation." (Y3-17-22)

Their active participation also facilitated learning, made them more engaged, and as mentioned earlier, more reflective of the inadequacies in their own communication styles. Some students

Formatted: Justified, Indent: First line: $1.27 \mathrm{~cm}$, Adjust space between Latin and Asian text, Adjust space between Asian text and numbers, Tab stops: Not at $1.27 \mathrm{~cm}+2.54 \mathrm{~cm}+3.81 \mathrm{~cm}+5.08 \mathrm{~cm}+6.35 \mathrm{~cm}+$ $7.62 \mathrm{~cm}+8.89 \mathrm{~cm}+10.16 \mathrm{~cm}+11.43 \mathrm{~cm}+12.7 \mathrm{~cm}$ $+13.97 \mathrm{~cm}+15.24 \mathrm{~cm}+16.51 \mathrm{~cm}+17.78 \mathrm{~cm}$ 
appreciated the fact that the scenarios reflected real-life situations in the pharmacy. This helped pique their interest as it aided in painting a picture of the kind of patients and scenarios they might encounter in the pharmacy on a daily basis, and gave them a taste of their future roles as pharmacists.

Many students relished the opportunity at being able to participate in the role-plays. It provided them with the opportunity to practice skills they had been taught in class and get a hands-on experience in applying concepts to 'real-life' situations, such as using the WWHAMM ${ }^{45}$ (Who is it for; What are the symptoms; How long have the symptoms been present; Any other medication being taken;

Medication tried already) Model, as noted by the following student: -

"In preparation of the [...] OSCE I felt that the role play activity whereby you had to communicate with an actor patient arriving at the pharmacy with a minor ailment was particularly useful. As well as being given the opportunity to hone communication skills, it was helpful in the practical implementation of the WWHAMM questioning and the ability to gather information and simultaneously allow the application of knowledge learned in lectures in a realistic setting. " (Y2-16-1)

\section{Theme 5: Students'suggestions for improvement}

A number of students expressed the desire to engage in more role-play activities where they get to act out different scenarios as a pharmacist with both the actors and their peers, noting that they found it very useful and helped them gain confidence. A few students also highlighted the need for more group work as it would give more people the opportunity to get involved, stressing that these should be undertaken in smaller groups as it would allow for more effective discussions and increased interactions. Furthermore, students were of the opinionfelt that smaller groups would encourage those who were reticent to participate, as they would feel more comfortable. Smaller groups were also thought to allow for more effective and personalized feedback to be given by the actors, as highlighted in the following response:-

"The students could be split into smaller groups and be given more of an opportunity to be involved in role play scenarios during the workshop and the $[.$.$] RolePlay UK team could critique their$ communication skills as well as offer them advice on how to improve their skill on an individual basis just to understand where their strengths and weaknesses lie.” (Y3-15-10)
Formatted: Font: Bold

Formatted: Justified, Indent: First line: $1.27 \mathrm{~cm}$, Widow/Orphan control, Adjust space between Latin and Asian text, Adjust space between Asian text and numbers, Tab stops: Not at $1.27 \mathrm{~cm}+2.54 \mathrm{~cm}+3.81$ $\mathrm{cm}+5.08 \mathrm{~cm}+6.35 \mathrm{~cm}+7.62 \mathrm{~cm}+8.89 \mathrm{~cm}+$ $10.16 \mathrm{~cm}+11.43 \mathrm{~cm}+12.7 \mathrm{~cm}+13.97 \mathrm{~cm}+15.24$ $\mathrm{cm}+16.51 \mathrm{~cm}+17.78 \mathrm{~cm}$ 

with the different types of patients one might encounter in a pharmacy such as a parent with a child, geriatric patients, patients with chronic conditions, and those with disabilities. There was also a comment that more hospital or industry scenarios should be incorporated, instead of solely focusing on community pharmacy. In addition, scenarios involving drugs related to the themes of the year of study were preferred, so that students would not have to make up information that they had no knowledge of. Related to that, students wanted more drug-related or pharmacy-related information which they had yet to learn provided to them before partaking in the role-play, as noted by one student, :

"When having students partake in role play as pharmacists to pretend to sell a drug, it may fit

11 the pharmacist agenda more strongly to provide the student with some info on the drug, as we were all in our beginning months of our first year in pharmacy, and [in order] to "flex" to customers, some information is required for different customer types. " (Y2-16-6)

Many students thoughtfelt the workshops were too long and repetitive, with a few losing interest after a while. It was suggested that it should be shortened to two hours to keep them engaged, kept concise to enable students to recall what was taught, and to have breaks to facilitate concentration and prevent fatigue. A few students expressed displeasure that they were not given enough information prior to the start of the workshop on what to expect of the workshop, as they could have come more prepared for the session. There were also requests for more handouts with explanations on the information provided during the workshop to be given, as this would reinforce the points made during the workshop, and help them understand the large volume of information received.

A few students lamented the lack of knowledge the actors had on pharmacy, reporting some inaccuracies in the information provided. There was, thus, a call for pharmacists to be involved in the workshop to role-play with, to see how they would react in each situation, and to share their experience on the different situations and personalities that they encounter during their job, as illustrated in the 
1 “...it may have been good to have an experienced pharmacist's input as the actors were often unsure

$2 \quad$ what was professional and what was not." (Y2-15-2)

3

\section{Discussion}

Overall, students perceived the workshops as helpful in increasing their verbal and nonverbal communication skills, and successful in keeping them engaged. The live, interactive nature which closely resembled scenarios in pharmacy, were appreciated by students as they were able to apply the skills they had learned, and gave them a sense of their future roles as pharmacists.

The main strength of the workshops was the use of experiential-based instruction with feedback to teach communications skills, a method shown to be more effective than instructional methods, which have instead resulted in a decline of communication skills learned over time. ${ }^{34,46,47}$ Experiential learning (EL) theories encourage student engagement and stress feedback. ${ }^{48}$ According to Kolb and Kolb, one of the six propositions that EL theory is built on is the fact that 'All learning is relearning. Learning is best facilitated by a process that draws out the students' beliefs and ideas about a topic so that they can be examined, tested, and integrated with new, more refined ideas. ${ }^{48}$ This is similar to the method adopted in the role-plays in our workshops, where students provided their views - based on their beliefs and personal communication styles - on what they perceived to be effective communication approaches. Through the scenarios, these beliefs were then examined and discussed, thereby allowing students to alter their initial beliefs, and 're-learn' effective communication techniques. The active participation also allowed students to physically apply the theories they had learned. ${ }^{24,32}$

Current pharmacy educational models, however, adopt a transmission model, relying on a didactic approach to teach fixed ideas - an approach which does not equip students with 'functioning knowledge' on how to communicate. ${ }^{24}$ This is in contrast to social constructivism, a concept adopted by higher education pedagogies, which stipulates that the process of constructing knowledge is facilitated through 'cooperative social interactions'. As the human mind can only absorb and grasp a certain volume and rate of new information, 'teaching by telling' would prove an ineffectual method.
Formatted: Justified, Don't adjust space between Latin and Asian text, Don't adjust space between Asian text and numbers, Tab stops: $1.27 \mathrm{~cm}$, Left $+2.54 \mathrm{~cm}$, Left $+3.81 \mathrm{~cm}$, Left $+5.08 \mathrm{~cm}$, Left $+6.35 \mathrm{~cm}$, Left +7.62 $\mathrm{cm}$, Left $+8.89 \mathrm{~cm}$, Left $+10.16 \mathrm{~cm}$, Left $+11.43 \mathrm{~cm}$, Left $+12.7 \mathrm{~cm}$, Left $+13.97 \mathrm{~cm}$, Left $+15.24 \mathrm{~cm}$, Left $+16.51 \mathrm{~cm}$, Left $+17.78 \mathrm{~cm}$, Left 
Thus, as the volume and complexity of information increases, so too does the need for active participation by the learner. ${ }^{49}$

Two important aspects of the workshop were the fact that the scenarios reflected real-life situations, and that feedback was provided. Pharmacists have found it challenging to apply their communication skills during practice, and this was thought to be due to the fact that the training they received was not in the context of real-life practice. ${ }^{25}$ Instead, when training mirrored pharmacy-related encounters, pharmacists could effectively apply the skills they learned. ${ }^{25}$ The use of real-world situations also serves to motivate students to study and engage with the topic. ${ }^{23}$ The repeated use of real-life situations and provision of positive feedback were also thought to negate the apprehension suffered by those who were reticent through habituation and increased confidence in their capabilities, respectively. ${ }^{22}$

Students praised the feedback received, echoing other studies where tutors who provided feedback were evaluated positively compared to those who did not. ${ }^{50,51}$ The methods to provide feedback to students in the workshop were varied: both direct and indirect methods were employed. By observing the effect of their suggestions on the flow and outcomes of the scenarios, students indirectly received feedback on the strengths and weaknesses of their suggestions. This was then used to make corrections and propose better suggestions. Direct feedback received from the facilitators were also used to improve the role-play sessions with peers. Thus, students received feedback immediately, and actively interacted with the feedback received, both of which are necessary for it to be effective. ${ }^{52,53}$ The latter supports the tenets of students as self-regulated learners, a philosophy subscribed to in higherorder learning. ${ }^{52}$ Feedback from an external party is also valuable as there is no pre-existing relationship between the provider and the students, allowing for more honest dialogues. ${ }^{28}$

It is interesting to note that many students wanted to actively participate in the session, given that pharmacy students have typically displayed reticence at speaking up or interacting in classrooms. ${ }^{54-}$ 57 This goes back to the discussion on training reflecting real-life situations for it to be effective. ${ }^{23,25}$ Communication generally occurs in casual social settings, which is in contrast to traditional teaching which takes place in more formal settings. In addition, in the latter, which adopts a teacher-fronted strategy, the onus is on the teacher to do all the talking, decide the content and flow of the session, and 
2 with opportunity to produce behaviour'.59 Instructional classrooms, thus, do not provide this 3 opportunity, perpetuating reticence. ${ }^{58}$ The workshop, which adopted a facilitator-oriented strategy 4 instead, encouraged a more informal setting and social interactions, and provided ample opportunities 5 for students to participate, thus mitigating reticence. ${ }^{58}$ Working in small groups also contributed to 6 this. $^{54}$

The workshop employed the think aloud method, where thoughts and feelings while performing a cognitive task are verbalized, and these are in turn subject to analysis and reflection. ${ }^{28,60,61}$ This encouraged self-reflection in students, another important component of self-regulated learning. ${ }^{23,62-64}$ Reflection is an important and necessary skill to facilitate or support patient-centered care, enabling the pharmacists to fully comprehend the patients' needs, concerns, and expectations; as well as their own values and feelings. ${ }^{14}$ It is also an effective tool for health professionals as by reflecting on their strengths and weaknesses, they are able to determine what are their own training needs, as well as develop confidence in their professional capabilities. ${ }^{65}$ Another strength of the workshops was that they

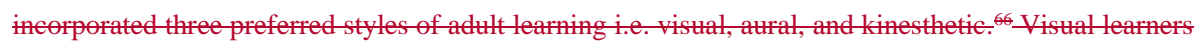

\section{Limitations}

As students already provided feedback on the workshop through the quantitative survey, some may have felt it was unnecessary to leave an open comment, which may have limited the number of comments received. Analysis of open-ended comments also did not allow the researchers to get more in-depth feedback from the students on themes identified. Future qualitative focus group discussions should thus be undertaken with students to allow a more comprehensive discussion to take place. In adopting such a workshop, challenges that might be faced are the cost of the workshop which could amount to approximately $£ 10$ per student per hour, as well as the fact that academics have little control over how the sessions will play out, given the improvisational nature of the sessions. ${ }^{28}$ 


\section{Summary}

Many current communication skills programs are ineffective in equipping future pharmacists as they are didactic in nature, do not mimic real-world situations, and do not provide immediate feedback to students. This series of communication workshops which employed an experiential-based instructional method where feedback was provided, role-playing was used, and which encouraged student participation and reflection; was positively received by students who felt it kept them engaged, and was effective in teaching them communication skills

\section{Acknowledgements}

The authors would like to thank the students for taking the time to give their feedback.

\section{References}

1. Patrícia Antunes L, Gomes JJ, Cavaco AM. How pharmacist-patient communication determines pharmacy loyalty? Modeling relevant factors. Research in Social and Administrative Pharmacy. 2015;11(4):560-570

2. Olsson E, Ingman P, Ahmed B, Kälvemark Sporrong S. Pharmacist-patient communication in Swedish community pharmacies. Research in Social and Administrative Pharmacy. 2014;10(1):149-155.

3. Shah B, Chewning B. Conceptualizing and measuring pharmacist-patient communication: a review of published studies. Research in Social and Administrative Pharmacy. 2006;2(2):153185.

4. Lyra DP, Rocha CE, Abriata JP, Gimenes FRE, Gonzalez MM, Pelá IR. Influence of Pharmaceutical Care intervention and communication skills on the improvement of pharmacotherapeutic outcomes with elderly Brazilian outpatients. Patient Education and Counseling. 2007;68(2):186-192. 
5. Koster ES, van Meeteren MM, van Dijk M, et al. Patient-provider interaction during medication encounters: A study in outpatient pharmacies in the Netherlands. Patient education and counseling. 2015;98(7):843-848

6. van Hulten R, Blom L, Mattheusens J, Wolters M, Bouvy M. Communication with patients who are dispensed a first prescription of chronic medication in the community pharmacy. Patient education and counseling. 2011;83(3):417-422.

7. Cavaco AM, Romano J. Exploring pharmacists' communication with customers through screening services. Patient education and counseling. 2010;80(3):377-383

8. Svensberg K, Björnsdottir I, Wallman A, Sporrong SK. Nordic Pharmacy Schools’ Experience in Communication Skills Training. American Journal of Pharmaceutical Education. 2017;81(9):6005.

10. Rickles NM, Young GJ, Hall JA, et al. Medication adherence communications in community pharmacies: A naturalistic investigation. Patient education and counseling. 2016;99(3):386392.

11. Kaae S, Mygind A, Saleem S. A characterization of the current communication patterns in Danish community pharmacies - An observational study. Research in Social and Administrative Pharmacy. 2013;9(6):958-964.

12. Kaae S, Traulsen JM, Nørgaard LS. Challenges to counseling customers at the pharmacy counter-Why do they exist? Research in Social and Administrative Pharmacy. 2012;8(3):253257.

13. Naughton CA. Patient-Centered Communication. Pharmacy. 2018;6(18):1-8.

14. Wolters M, van Hulten R, Blom L, Bouvy ML. Exploring the concept of patient centred communication for the pharmacy practice. International journal of clinical pharmacy. 2017;39(6):1145-1156 
15. Sepucha K, Ozanne EM. How to define and measure concordance between patients' preferences and medical treatments: A systematic review of approaches and recommendations for standardization. Patient Education and Counseling. 2010;78(1):12-23.

16. Kerr A, Strawbridge J, Kelleher C, et al. How can pharmacists develop patient-pharmacist communication skills? A realist review protocol. Systematic Reviews. 2017;6(1):14.

17. Murad MS, Chatterley T, Guirguis LM. A meta-narrative review of recorded patientpharmacist interactions: Exploring biomedical or patient-centered communication? Research in Social and Administrative Pharmacy. 2014;10(1):1-20.

18. Wiedenmayer K, Summers RS, Mackie CA, et al. Developing pharmacy practice : a focus on patient care : handbook. Geneva: World Health Organization; 2006.

19. International Pharmaceutical Federation. FIP Statement of Policy on Good Pharmacy Education Practice FIP Council; 2000; Vienna, Austria.

20. Stevenson FA, Cox K, Britten N, Dundar Y. A systematic review of the research on communication between patients and health care professionals about medicines: the consequences for concordance. Health Expectations : An International Journal of Public Participation in Health Care and Health Policy. 2004;7(3):235-245.

21. Coulter A, Ellins J. Effectiveness of strategies for informing, educating, and involving patients. BMJ. 2007;335(7609):24-27.

22. Mesquita AR, Lyra DP, Brito GC, Balisa-Rocha BJ, Aguiar PM, de Almeida Neto AC. Developing communication skills in pharmacy: A systematic review of the use of simulated patient methods. Patient Education and Counseling. 2010;78(2):143-148.

23. Hyvärinen M-L, Tanskanen P, Katajavuori N, Isotalus P. A Method for Teaching Communication in Pharmacy in Authentic Work Situations. Communication Education. 2010;59(2):124-145.

24. Middlewick Y, Kettle TJ, Wilson JJ. Curtains up! Using forum theatre to rehearse the art of communication in healthcare education. Nurse Education in Practice. 2012;12(3):139-142.

25. Abillio CDAN, Benrimoj SI, Kavanagh DJ, Boakes RA. Novel educational training program for community pharmacists. American Journal of Pharmaceutical Education. 2000;64(3):302. 
26. Beardsley RS. Communication skills development in colleges of pharmacy. American Journa of Pharmaceutical Education. 2001;65(4):307.

27. Gallimore C, George AK, Brown MC. Pharmacy Students' Preferences for Various Types of Simulated Patients. American Journal of Pharmaceutical Education. 2008;72(1):4.

28. Bell SK, Pascucci R, Fancy K, Coleman K, Zurakowski D, Meyer EC. The educational value of improvisational actors to teach communication and relational skills: Perspectives of interprofessional learners, faculty, and actors. Patient Education and Counseling. 2014;96(3):381-388.

29. Smigiel H, Merritt L. A new approach to communication training in the workplace. Journal of Vocational Education \& Training. 1999;51(4):629-640.

30. James D, Nastasic S, Horne R, Davies G. The design and evaluation of a simulated-patient teaching programme to develop the consultation skills of undergraduate pharmacy students. Pharm World Sci 2001;23(6):212-216.

31. Corelli RL, Kroon LA, Chung EP, et al. Statewide evaluation of a tobacco cessation curriculum for pharmacy students. Preventive Medicine. 2005;40(6):888-895.

32. Rao D. Skills Development Using Role-Play in a First-Year Pharmacy Practice Course. American Journal of Pharmaceutical Education. 2011;75(5):84.

33. Luiz Adrian JA, Zeszotarski P, Ma C. Developing Pharmacy Student Communication Skills through Role-Playing and Active Learning. American Journal of Pharmaceutical Education. $2015 ; 79(3): 44$.

34. Lane C, Rollnick S. The use of simulated patients and role-play in communication skills training: A review of the literature to August 2005. Patient Education and Counseling. 2007;67(1):13-20.

35. Boesen KP, Herrier RN, Apgar DA, Jackowski RM. Improvisational Exercises to Improve Pharmacy Students' Professional Communication Skills. American Journal of Pharmaceutical Education. 2009;73(2):35.

36. Hartman JL, McCambridge J. Optimizing Millennials' Communication Styles. Business Communication Quarterly. 2011;74(1):22-44. 
37. Qualtrics Experience Management Platform. Qualtrics. 2018.

38. Bankauskaite V, Saarelma O. Why are people dissatisfied with medical care services in Lithuania? A qualitative study using responses to open-ended questions. International Journal for Quality in Health Care. 2003;15(1):23-029.

39. Steckler A, McLeroy KR, Goodman RM, Bird ST, McCormick L. Toward Integrating Qualitative and Quantitative Methods: An Introduction. Health Education Quarterly. $1992 ; 19(1): 1-8$

40. O'Cathain A, Thomas KJ. "Any other comments?" Open questions on questionnaires - a bane or a bonus to research? BMC Medical Research Methodology. 2004;4:25-25.

41. Cassidy CM. Chinese Medicine Users in the United States Part II: Preferred Aspects of Care. The Journal of Alternative and Complementary Medicine. 1998;4(2):189-202.

42. Handling Qualitative Data: A Practical Guide [computer program]. London: Sage Publications; 2005.

43. Saldana J. The Coding Manual for Qualitative Researchers. 3rd ed. London: Sage Publications Ltd; 2016.

44. Cook S. Coaching for High Performance: How to develop exceptional results through coaching (Soft Skills for It Professionals). Cambridgeshire, United kingdom: IT Governance Ltd; 2009.

45. Anon. NPA launches training with a W-WHAM. Pharm J 1989;243(40).

46. Aspegren K. BEME Guide No. 2: Teaching and learning communication skills in medicine-a review with quality grading of articles. Medical teacher. 1999;21(6):563-570.

47. Hess R, Hagemeier NE, Blackwelder R, Rose D, Ansari N, Branham T. Teaching Communication Skills to Medical and Pharmacy Students Through a Blended Learning Course. American Journal of Pharmaceutical Education. 2016;80(4):64.

48. Kolb AY, Kolb DA. Learning Styles and Learning Spaces: Enhancing Experiential Learning in Higher Education. Academy of Management Learning \& Education. 2005;4(2):193-212.

49. Eberlein T, Kampmeier J, Minderhout V, et al. Pedagogies of engagement in science. Biochemistry and Molecular Biology Education. 2008;36(4):262-273. 
50. Mete S, Yildirim Sari H. Nursing students' expectations from tutors in PBL and effects of tutors' behaviour on nursing students. Nurse Education Today. 2008;28(4):434-442.

51. McLean MM. Communicating curriculum reform to students: Advice in hindsight. $B M C$ Medical Education. 2003;3:1-10.

52. Nicol DJ, Macfarlane-Dick D. Formative assessment and self-regulated learning: a model and seven principles of good feedback practice. Studies in Higher Education. 2006;31(2):199-218.

53. Rust C, O’Donovan B, Price M. A social constructivist assessment process model: how the research literature shows us this could be best practice. Assessment \& Evaluation in Higher Education. 2005;30(3):231-240.

54. Mehvar R. A Participation Requirement to Engage Students in a Pharmacokinetics Course Synchronously Taught at a Local and Distant Campus. American Journal of Pharmaceutical Education. 2010;74(7):118.

55. Khan T M, Ejaz M A, Azmi S. Evaluation of Communication Apprehension among First Year and Final Year Pharmacy Undergraduates. . Journal of Clinical and Diagnostic Research. 2009;3:1885-1890

56. LaRochelle JM, Karpinski AC. Racial Differences in Communication Apprehension and Interprofessional Socialization in Fourth-Year Doctor of Pharmacy Students. American Journal of Pharmaceutical Education. 2016;80(1):8.

57. Berger B, Baldwin HJ, McCroskey JC, Richmond VP. Communication Apprehension in Pharmacy Students: A National Study. Vol 471983.

58. Lee W, Ng S. Reducing student reticence through teacher interaction strategy. ELT Journal. 2010;64(3):302-313.

59. MacIntyre PD, xf, rnyei Z, et al. Conceptualizing Willingness to Communicate in a L2: A Situational Model of L2 Confidence and Affiliation. The Modern Language Journal. $1998 ; 82(4): 545-562$

60. Lingemann K, Campbell T, Lingemann C, Hölzer H, Breckwoldt J. The Simulated Patient's View on Teaching: Results From a Think Aloud Study. Academic Medicine. 2012;87(2):179184. 
61. Fonteyn ME, Kuipers B, Grobe SJ. A Description of Think Aloud Method and Protocol Analysis. Qualitative Health Research. 1993;3(4):430-441.

62. Papinczak T, Young L, Groves M, Haynes M. An analysis of peer, self, and tutor assessment in problem-based learning tutorials. Medical teacher. 2007;29(5):e122-e132.

63. Eva KW, Cunnington JPW, Reiter HI, Keane DR, Norman GR. How Can I Know What I Don't Know? Poor Self Assessment in a Well-Defined Domain. Advances in Health Sciences Education. 2004;9(3):211-224.

64. Medina MS. Teaching Self-concept and Self-esteem in a Clinical Communications Course. American Journal of Pharmaceutical Education. 2006;70(5):99.

65. Eva KW, Regehr G. Self-Assessment in the Health Professions: A Reformulation and Research Agenda. Academic Medicine. 2005;80(10):S46-S54.

66. Conner M. Adult Learning Styles. In: Seel NM, ed. Encyclopedia of the Sciences of Learning. Boston, MA: Springer US; 2012:138-141. 